\title{
A Theoretical Approach to Information Needs Across Different Healthcare Stakeholders
}

\author{
Reetta Raitoharju ${ }^{1}$ and Eeva Aarnio ${ }^{2}$ \\ 1 Turku School of Economics, Information Systems Science \\ Rehtorinpellonkatu 3, 20500 Turku, Finland. \\ reetta.raitoharju@tse.fi \\ 2 Turku School of Economics, Information Systems Science \\ Rehtorinpellonkatu 3, 20500 Turku, Finland. \\ eeva.aamio@tse.fi
}

\begin{abstract}
Increased access to medical information can lead to information overload among both the employees in the healthcare sector as well as among healthcare consumers. Moreover, medical information can be hard to understand for consumers who have no prerequisites for interpreting and understanding it. Information systems (e.g. electronic patient records) are normally designed to meet the demands of one professional group, for instance those of physicians. Therefore, the same information in the same form is presented to all the users of the systems regardless of the actual need or prerequisites. The purpose of this article is to illustrate the differences in information needs across different stakeholders in healthcare. A literature review was conducted to collect examples of these different information needs. Based on the findings the role of more user specific information systems is discussed.
\end{abstract}

\section{Introduction}

Healthcare sector is an information intensive field and, therefore, information can be seen as the most important asset of the sector. However, despite the increased use of clinical information technology, healthcare professionals often have problems in finding the needed information [1]. This, obviously, is a problem since wellmanaged information is said to be one of the most important resources in clinical

Please use the following format when citing this chapter:

Raitoharju, R., Aamio, E, 2007, in IFIP Intemational Federation for Information Processing, Volume 252, Integration and Innovation Orient to E-Socicty Volume 2, cds. Wang, W., (Boston: Springer), pp. 497-504. 
practice. The collection, transmission, storage, and retrieval of information are crucial for most healthcare activities and, therefore, access to information is a prerequisite for evidence-based practice and coordination of care. [2]

However, the increased access to medical information can lead to information overload among the clinicians [3] as well as among the healthcare consumers [4]. Health information is one of the most searched topic in Internet [5] and as there is an increasing interest in reaching healthcare consumers through different information systems for instance through Internet, a variety of applications have been launched. At its best information systems are cost-effective and timesaving. However, studies have found that the effects can also be negative such as doctors feeling threatened by the information the patient brings to the consultation [5].

Another problem related to medical information is that understanding medical information requires specific abilities that not everybody has. For instance, Internet users searching for medical information go to sites aimed at health professionals [5]. This is a problem since the medical information has been stated to be created for the professionals, not the public [6]. Health literacy - the ability to understand and act on health information has been addressed to be one of the most pressing issues in healthcare. Medical information is produced by and targeted to several categories of users and public consumers have found to have difficulties in finding, understanding and acting on health information due to their lack of domain knowledge [7]. The mediating role of language has been recognized and it is important for instance in development of medical artificial intelligence and terminologies and nomenclatures has been noticed [8]. Multidisciplinary organizations are essential part of healthcare and the medical treatment of a patient takes place often in multidisciplinary teams consisting of physicians, nurses, pharmacists as well as non medical persons such as family or friends. Given such, it is very challenging to make the medical information understandable and accessible for all the parties without exposing them to an information overload or the risk of misinterpreting information.

In order to avoid the problems of information overload and challenges in understanding and interpreting medical information, it should be more specifically personalized to different users and filtered from unnecessary or even wrong information. Information systems designed to meet the needs of certain group of users may be of much less use to others. To maximize the benefits of the medical information, it should be easy to find and easy to understand. Therefore, in this article we illustrate the information needs in the healthcare setting across different healthcare stakeholders: physicians, nurses and healthcare consumers. By information need we understand "an expression of missing information needed to perform a particular task" [ 9 p. 247]. The purpose of this article is to examine the previous studies about the information needs of different user groups in the medical treatment process. The study is conducted as a non-systematic literature review without an intention to be a meta-analysis. The aim is illustrate the main differences in the information needs in healthcare.

This article is structured as follows. First, the information needs perspective is presented. Then the different information needs of physicians, nurses and healthcare consumers are discussed based on previous literature. Finally, examples are presented to help understand the different information needs of different healthcare stakeholders. The purpose of this paper in short is to approach theoretically the 
different information needs of healthcare professionals and discuss how personalizing information systems could help to avoid current problems.

\section{Information needs in the healthcare}

There has not been an established way to identify existing information needs in the health care setting [10]. What has been widely noticed is that if the access to needed information is limited and communication is not efficient, errors are more probable to happen in-patient care [11]. However, decision making by healthcare professionals is often complicated by the need to integrate ill-structured, uncertain and conflicting information from various sources [12]. Besides the formal sources of information, the information needs can be often met by collaboration with other individuals, such as clinical team members [13]. To find the needed information, team members often search multiple resources and collaborate with different team members (e.g. physician asks the secretary to find the lab results). There are usually many different components of the information that need to be combined to treat the patient and choose the right medication such as medical condition of the patient, his/her weight, pain rating, symptoms and pain location)[14].

In team-oriented healthcare environments (e.g. intensive care unit) the information needs differ from those in other organizational settings [13] and the information needs are also unique in each clinical unit [15]. Besides the differences between the units, there are also variation in the use of information resources and information searching techniques on personal level, whereupon the way to meet the information needs could also be different within a unit. However, the required information resources should always be available when the clinician has identified the information need [16]. In the units where multidisciplinary information is needed, the information needs are more attached to the domain of the clinician whereas the information needs in narrowly constrained domains such as cardiology, could be from other domains [17]. In a study about an emergency department team's information needs were found to be most crucial when the professionals had fragmented information resources or when the information need was complex or when they were lacking expertise [14].

Based on other researchers' studies, Gorman $[10,732]$ has identified the states of information needs. According to him, there are unrecognized, recognized, pursued and satisfied needs. In the first case, information cannot be pursued because the need is not recognized [see also 17]. When the need is recognized, it may or may not be pursued. In the case of seeking the information, the seeking is not always successful. The information seeking could be unsuccessful for instance due to information flow breakdown. Three reasons for the information flow breakdown were identified by Reddy and Spence [18]: information was not available when it was supposed to be available, the information was incorrect or incomplete, and the information was delivered to a wrong person.

Besides the clinical staff, the patients also need health information and the differences between the needs are influenced by demographic factors. The information is extremely important for the patients themselves especially when they 
have got some serious illness e.g. cancer. When it comes to the patients the information needs vary for instance according to their age, education, and gender. [19] Patients can also be important sources of information for other patients because of their experience related to their illness and disease [20].

\subsection{Information needs of physicians}

Published studies of physicians' information needs have reported fluctuating results. In order to interpret and compare physicians information needs Gorman [10] build a framework based on a literature review for classification of the information that clinicians use when caring for patients (Table 2).

Table 1 Types of information used by clinicians [10 p. 730]

\begin{tabular}{|l|l|l|}
\hline Type of information & Description & Examples \\
\hline Patient data & $\begin{array}{l}\text { Refers to a single } \\
\text { person }\end{array}$ & $\begin{array}{l}\text { Medical history, Physical exam, } \\
\text { Laboratory data }\end{array}$ \\
\hline Population statistics & Aggregate patient data & $\begin{array}{l}\text { Recent patterns of illness, Public health } \\
\text { data }\end{array}$ \\
\hline Medical knowledge & $\begin{array}{l}\text { Generalizable to many } \\
\text { persons }\end{array}$ & $\begin{array}{l}\text { Original research, Textbook } \\
\text { descriptions, Common knowledge }\end{array}$ \\
\hline Logic information & How to get the job done & $\begin{array}{l}\text { Required form, Preferred consultant, } \\
\text { Covered procedure }\end{array}$ \\
\hline Social influences & $\begin{array}{l}\text { How others get the job } \\
\text { done }\end{array}$ & Local practice patterns \\
\hline
\end{tabular}

Patient data includes items of a patient's history, recent symptoms, and diagnostic test results. Population statistics refers to data about groups or populations of patients whereas medical knowledge refers to information that is understood to be generalizible to the care of all patients. Logistic Information includes local knowledge about how to get the job done and finally Social Influences refers to knowledge about expectations and beliefs of others such as colleagues and also family. [10]

\subsection{Information needs of nurses}

The main problem the nurses encounter when searching for information was using the databases, being unaware of the sources, lack of familiarity, accessing what they want and lack of time [21]. In a study about the demands of PDA the need to make the information in general richer was stated. Especially nurses expected access to information about the patients, knowledge resources and functions for their daily work. Some nurses addressed the problem that they had spent a lot of time searching for medical information in books and memos. [22]

The patient information that the nurses wanted was, for instance, schedule displaying the patients' stay, and test results. There was a need to easily know where 
the patient is located and what the needs are during the stay. It was important also to pass this information to the relatives' and answer their questions. [22].

The need for knowledge database was also expressed. This would optimally include reference books, dictionaries, practical handbooks and internal memos. Internal memos both from nurses' own ward and other wards are important to get information about procedures e.g. preparations before surgery. Especially access to an electronic pharmaceutical record with a handheld devices was named to be important [22]. It has also been seen as a problem that the rehabilitation information is not necessarily consistent coming from different surgeons in a day surgery to patients. Especially to nurses working on a busy day-unit where there are patients from different hospitals [23].

\subsection{Information needs of healthcare consumers}

Effective communication is said to be key to optimal health outcomes [24]. However, the research about the information needs of the healthcare consumers has mostly concentrated on information needs of the patients with a certain diagnosis [e.g. 25, $26,27]$. Although, this is obviously important a more general approach to estimate the specific information needs of the healthcare consumers should be taken. A review of research of information needs and sources among cancer patients found the most important information needs to be: cancer specific information, treatmentrelated information, prognosis information, rehabilitation information, surveillance and health information, coping information, interpersonal/social information, financial/legal information, medical system information and body image/sexuality information [24].

Cancer specific information consisted of information such as type of cancer, stage of disease, physical effects of disease and seeking second opinions. Treatmentrelated information was for instance, side effects of treatment, tests and procedures involved in treatment, alternative or complimentary treatments or referrals for treatment. Prognosis information included information like chance of cure, life span or survival rate or options if initial treatment fails. Rehabilitation information consisted of information such as self care issues or home care during recovery, nutrition during recovery or recovery time. Surveillance and health information was maintaining physical health or physical activity, prevention and early detection or health behavior and promotion. Coping information included information such as emotional reactions, support groups or community counseling or support. Interpersonal/social information was the effect on family, friends, or caregivers, effect on social life or leisure or effect on employment. Financial/legal information consist information like cost of treatment, insurance coverage, or other financial issues as well as advanced directives or writing a will. Medical system information is information about interactions with healthcare providers, health care systems or experience or qualifications of physician and medical staff. [24]

Nowadays, patients have less time to ask advice about the rehabilitation form their surgeons. It was also stated that the advice the patients feel they need may not necessarily be the same as those areas identified as important by professionals such as is it safe to vacuum clean or have sex after the surgery [23]. Problems identified 
with hospital post-operative information leaflets were according to Bradshaw et al. [23] the lack of precision, jargon and difficulties to read.

\section{Comparisons of the information needs in healthcare}

The development of information systems in the healthcare is often executed without consulting the personnel or the healthcare customers. Besides leading to systems that are not easy to use the systems can offer information that does not meet the needs of the different focus groups. In an evaluation of an electronic patient information system for children with amblyopia and their parents it appeared that the system was little used because of the needs of those people who actually would be using the system had never really been investigated [28]. It can be stated that the medical information systems often are designed from the perspective of the physicians information needs.

Table 2 below summarizes examples of different information needs found in previous literature.

Table 2 Comparision of types of information needs in the healthcare

\begin{tabular}{|c|c|c|c|}
\hline $\begin{array}{c}\text { Type of } \\
\text { information }\end{array}$ & $\begin{array}{l}\text { Physicians } \\
\text { (adapted from } \\
\text { Gorman 1995) }\end{array}$ & Nurses & $\begin{array}{c}\text { Healthcare } \\
\text { consumers (adapted } \\
\text { from Finney Rutten et } \\
\text { al. 2005) } \\
\end{array}$ \\
\hline Patient data & $\begin{array}{l}\text { Medical history, } \\
\text { physical exam, } \\
\text { laboratory data }\end{array}$ & $\begin{array}{l}\text { Schedule displaying the } \\
\text { patients' stay, location } \\
\text { and needs during the } \\
\text { stay and test results }\end{array}$ & $\begin{array}{l}\text { Prognosis information, } \\
\text { treatment information }\end{array}$ \\
\hline $\begin{array}{l}\text { Population } \\
\text { statistics }\end{array}$ & $\begin{array}{l}\text { Recent patterns of } \\
\text { illness, public health } \\
\text { data }\end{array}$ & $\mathrm{n} / \mathrm{a}$ & $\begin{array}{l}\text { Other patients' } \\
\text { experiences or choices } \\
\text { about treatment, } \\
\text { Recovery times }\end{array}$ \\
\hline $\begin{array}{c}\text { Medical } \\
\text { knowledge }\end{array}$ & $\begin{array}{l}\text { Original research, } \\
\text { textbook } \\
\text { descriptions, } \\
\text { common knowledge }\end{array}$ & $\begin{array}{l}\text { Pharmaceutical record, } \\
\text { reference books, } \\
\text { dictionaries, practical } \\
\text { handbooks and internal } \\
\text { memos }\end{array}$ & $\begin{array}{l}\text { Nature and effects of } \\
\text { disease, information } \\
\text { sources of disease }\end{array}$ \\
\hline $\begin{array}{c}\text { Logic } \\
\text { information }\end{array}$ & $\begin{array}{l}\text { Required form, } \\
\text { preferred consultant, } \\
\text { covered procedure }\end{array}$ & $\begin{array}{l}\text { Functions for daily } \\
\text { work }\end{array}$ & $\begin{array}{l}\text { Cost of treatment or } \\
\text { other financial issues, } \\
\text { advance directives or } \\
\text { writing a will, medical } \\
\text { system information }\end{array}$ \\
\hline $\begin{array}{c}\text { Social } \\
\text { influences }\end{array}$ & $\begin{array}{l}\text { Local practice } \\
\text { patterns }\end{array}$ & $\begin{array}{l}\text { Information to the } \\
\text { relatives' and answer } \\
\text { their questions }\end{array}$ & $\begin{array}{l}\text { Effect and risks on } \\
\text { family, friends, } \\
\text { caregivers, work life, } \\
\text { social life, sex life }\end{array}$ \\
\hline $\begin{array}{l}\text { Rehabilitation } \\
\text { information }\end{array}$ & $\mathrm{n} / \mathrm{a}$ & $\begin{array}{l}\text { Consistent information } \\
\text { from surgeons }\end{array}$ & $\begin{array}{c}\text { Self care issues, } \\
\text { nutrition information }\end{array}$ \\
\hline
\end{tabular}




\section{Discussion}

The preliminary research review illustrates the different, and at the same time overlapping information needs of different healthcare stakeholders. As found in previous literature information needs at a meta-level are very similar. However, there are differences in scope of need and the form in which the information should be available to the stakeholders. For instance, the important logic information needed by a physician to treat a patient is to know the required form whereas to patient it can be the cost of treatment. Therefore, taking into consideration the different needs of different stakeholders when planning the information systems could enable more personalized inquiries of medical information.

\section{REFERENCES}

1. M.C. Reddy and W. Pratt, Asking questions: Information needs in a surgical intensive care unit. American Medical Informatics Association Fall Symposium, (2002)

2. A. Moen, A nursing perspective to design and implementation of electronic patient record systems. Journal of Biomedical Informatics. 36,375-378 (2003)

3. R.E. Hunt and R.G. Newman, Medical knowledge overload: a disturbing trend for physicians. Health Care Management Review. 22(1),70-75 (1997)

4. K. Ankem, Factors influencing information needs among cancer patients: A metaanalysis. LIbrary \& Information Scinece Research. 28,7-23 (2006)

5. M. McMullan, Patients using the Internet to obtain health information: How this affects the patient-health professional relationship. Patient Education and Counseling. 63,24-28 (2006)

6. M. Kisilowska, Knowledge management prerequisites for building an information society in healthcare. International Journal of Medical Informatics. 75,322-329

(2006)

7. Q.T. Zeng and T. Tse, Exploring and developing consumer health vocabularies. Journal of the American Medical Informatics Association. 13(1),24-29 (2006)

8. T. Timpka, Situated clinical cognition. Artificial Intelligence in Medicine. 7(5),387-394 (1995)

9. L.M.M. Braun, et al., Towards patient-related information needs. International Journal of Medical Informatics. 76,246-251 (2007)

10. P.N. Gorman, Information needs of physicians. Journal of the American Society for Information Science. 46(10),729-736 (1995)

11. E.A. Mendonca, et al., Approach to mobile information and communicatipn for health care. International Journal of Medical Informatics. 73,631-638 (2004)

12. A.W. Kushniruk, Analysis of complex decision-making process in health care: Cognitive approaches to health informatics. Journal of Biomedical Informatics.

34,365-376 (2001)

13. M.C. Reddy, et al. Asking Questions: Information Needs in a Surgical Intensive

Care Unit. in Proceedings of the American Medical Informatics Association Fall

Symposiun AMIA'02. 2002. San Antonio, TX. 
14. M.C. Reddy and P.R. Spence, Collaborative information seeking: A field study of a multidisciplinary patient care team. Information Processing and Management. Article in press (2007)

15. R.N. Jerome, et al., Information needs of clinical teams: analysis of questions received by the Clinical Informatics Consult Service. Bulletin of the Medical Library Association. 89(2),177-185 (2001)

16. K.A. McKibbon and D.B. Fridsma, Effectiveness of Clinician-selected Electronic Information resources for Answering primary care Physicians' Information Needs. Journal of the American Medical Informatics Association. 13(6),653-659 (2006) 17. L.M.M. Braun, et al., Towards patient-related information needs. International Journal of Medical Informatics. 76(2-3),246-251 (2007)

18. M.C. Reddy and P.R. Spence, Collaborative information seeking: A field study of a multidisciplinary patient care team. Information processing \& management.

Article in press (2007)

19. K. Ankem, Factors influencing information needs among cancer patients: A meta-analysis. Library \& Information Science Research. 28(1),7-23 (2006)

20. K.M. Åkesson, B.-I. Saveman, and G. Nilsson, Health care consumers' experiences of information communication technology - A summary of literature. International Journal of Medical Informatics. Article in press. (2006)

21. P.J. Stokes and D. Lewin, Information-seeking behaviour of nurse teachers in a school of health studies: a soft systems analysis. Nurse Education Today. 24,47-54 (2004)

22. M. Berglund, et al., Nurses' adn nurse students' demands of functions and usability in a PDA. International Journal of Medical Informatics. Article in press (2006)

23. C. Bradshaw, et al., Information needs of general day surgery patients. Ambulatory surgery. 7(39-44) (1999)

24. L.J. Finney Rutten, et al., Information needs and sources of information among cancer patiens: a systematic review of research (1980-2003). Patient Education and Counseling. 57,250-261 (2005)

25. I. Mesters, et al., Measuring information needs among cancer patients. Patient Education and Counseling. 43(3),255-264 (2001)

26. D. Casarett, et al., Obtaining informed consent for clinical pain research: patients' concerns and information needs. Pain. 92(1-2),71-79 (2001)

27. S.F. Zarbock, Meeting the Information Needs of Patients with Metastatic Breast Cancer. Home Care Provider. 6(1),37-40 (2001)

28. van't Riet Annemarie, et al., Meeting patients' needs with patient information systems: potential benefits of qualitative research methods. International Journal of Medical Informatics. 64(1-14) (2001) 